\title{
Tuning PCP-Ir Complexes: The impact of an N-Heterocyclic Olefin
}

Manuel Iglesias, ${ }^{* a}$ Amaia Iturmendi, ${ }^{a}$ Pablo J. Sanz Miguel, ${ }^{a}$ Victor Polo, ${ }^{b}$ Jesús J. PérezTorrente, ${ }^{a}$ Luis A. Oro*a,

A new PCP-type ligand based on an N-heterocyclic olefin (NHO) scaffold has been prepared. The flexibility of this ligand, which is able to adopt facial coordination modes in $\operatorname{Ir}(I)$ or meridional in $\operatorname{Ir}($ III) complexes, can be attributed to the dual nature ylide-olefin of the NHO scaffold. This results in a rare case of olefin "slippage" that is supported by X-ray crystallography and DFT calculations.

The search for neutral ligands with strong $\sigma$-donor ability has been a continuous endeavour for organometallic chemists in the last few decades.[1] Initially phosphanes and later $\mathrm{N}$ heterocyclic carbenes ( $\mathrm{NHC}^{\prime}$ s) have met with great success as ancillary ligands for late transition metals in homogeneous catalysis.[2] The highly electron-rich metal centres obtained by coordination of strong $\sigma$-donating ligands are more prone to undergo oxidative addition and, consequently, bond activation can be achieved under milder conditions.[3]

$\mathrm{N}$-Heterocyclic olefins (NHO's) have proved to be remarkably strong electron-donating ligands able to unveil unprecedented reactivities. [4] Analyses of IR vibration frequencies of a range of [RhCl(CO)2L] complexes reveals that NHO's are stronger Lewis bases than analogous NHC's. [5] The unusual behaviour of this class of olefins is originated by the strongly polarized nature of the $\mathrm{C}=\mathrm{C}$ bond. The capacity of the $\mathrm{N}$-heterocyclic ring to accommodate a positive charge results in the stabilization of ylidic canonical forms II and III (Scheme 1). As a consequence of this, the terminal carbon atom is strongly nucleophilic, which results in an end-on coordination mode when acting as ligand for transition metals.[4a-b,5]

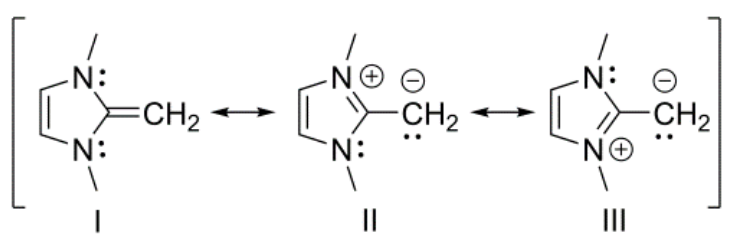

Scheme 1. Resonance structures for a generic NHO.

Despite the unusual properties of NHO's, the chemistry of this new class of ligands has been scarcely studied so far, perhaps due to the low stability of their transition metal complexes.[5]

A great variety of pincer complexes has been reported in the literature.[6] In particular, transition metal complexes containing PCP pincer ligands have shown remarkable catalytic activities in relevant reactions, such as, alkane dehydrogenation[7] or transfer hydrogenation. 8 In this regard, the nature of the scaffold and structure of pincer ligands have proved to be crucial features that determine the catalytic activity of their organometallic complexes.[6c,e] For example the metallocene-based PCP ligands reported by Koridze et al. are remarkably more active for the dehydrogenation of alkanes than those based on a benzene skeleton.[9]

In this work we report on the synthesis and reactivity of iridium complexes featuring the first PCP ligand based on an NHO scaffold (NHO = N-heterocyclic olefin). Moreover, the 
coordination mode of the ligand core $(\mathrm{NHO})$ in the $\operatorname{Ir}(\mathrm{I})$ and $\operatorname{Ir}(\mathrm{III})$ complexes described here represents a rare case of olefin "slippage" that has been studied by X-ray crystallography and DFT calculations.

The in situ deprotonation of 1,3-bis(2-(diphenylphosphino)ethyl)-2-methylimidazolium chloride (1)‡ (see Supporting Information for preparation) with KtBuO in dry THF affords the corresponding $\mathrm{NHO}$, which reacts with 0.5 equivalents of $[\operatorname{Ir}(\mu-\mathrm{Cl})(\operatorname{cod})] 2$ to yield $[\operatorname{Ir}(\mathrm{PCP})(\mathrm{cod})] \mathrm{Cl}(2)$, where PCP = 1,3-bis(2-(diphenylphosphanyl)ethyl)-2-methyleneimidazoline and $\operatorname{cod}=1,5$-cyclooctadiene (Scheme 2). Complex $[\operatorname{Ir}(\mathrm{PCP})(\operatorname{cod})] \mathrm{PF} 6(3)$ was prepared by reaction of 2 with 1 equivalent of AgPF6 in order to ease the crystallization process (Scheme 2). The most diagnostic peaks in the $1 \mathrm{H}$ NMR spectra of complexes 2 and 3 are those of the imidazole ring, which appear as singlets at $\delta 6.50$ and $5.96 \mathrm{ppm}$, respectively. In addition, the multiplets that correspond to the diastereotopic protons of the two $\mathrm{NCH} 2$ groups appear at $\delta$ 4.41-4.24 and 4.69-4.54 ppm for 2 , and $\delta 5.00-4.84$ and $4.64-4.50 \mathrm{ppm}$ for 3 . The 13C NMR spectra show triplets at $\delta 160.6$ ppm for 2 and 161.2 ppm for 3, both with a JC-P of $3.4 \mathrm{~Hz}$, which can be attributed to the terminal carbon atom of the $\mathrm{NHO}(\mathrm{CH} 2 \mathrm{Ir})$. This assignment is further supported by $1 \mathrm{H}-13 \mathrm{C}$ HSQC experiments as, in both cases, the 13C NMR peak shows a correlation with the broad singlet corresponding to the $\mathrm{CH} 2 \mathrm{Ir}$ protons at $\delta$ ca. $2.4 \mathrm{ppm}$. Remarkably, the carbon atoms of one of the olefins in the cod ligand, in 2 and 3, do not show $\mathrm{P}-\mathrm{C}$ coupling constants, which suggests that one of the olefins may dissociate in solution. The 31P NMR spectra of 2 and 3 show a broad singlet at $\delta-23.3$ and $-24.4 \mathrm{ppm}$, respectively, that correspond to the PPh2 groups. Variable temperature 31P NMR experiments reveal the fluxional behaviour of these complexes (see Supporting Information). At low temperatures the broad singlet turns into a set of two doublets $(2 \mathrm{JP}-\mathrm{P}=15 \mathrm{~Hz})$ at $\delta-18.7$ and $-28.3 \mathrm{ppm}$ for 3 , which suggests that both phosphorus nuclei become inequivalent due to two different conformations of the 7-membered metallacycles. The conformation of one metallacycle entails the axial phenyl ring of the phoshane pointing towards the cod ligand, while the axial phenyl ring of the other phosphane is directed to the imilazolium ring in the metallacycle. Variable temperature 31P NMR spectra of 3 (see Supporting Information) present the symmetry expected for a symmetrical two-site exchange and has a free energy ( $\Delta \mathrm{G} \ddagger)$ of $43 \mathrm{KJ}$ mol-1 (10.3 kcal mol-1) calculated according to equation $\Delta \mathrm{G} \ddagger=-\mathrm{RT} \operatorname{Ln}[\pi \Delta v 0 \mathrm{~h} /(21 / 2) \mathrm{kBTc}]$. The 31P NMR spectra also show a septuplet $(1 \mathrm{JP}-\mathrm{F}=712 \mathrm{~Hz})$ at $\delta-144.3 \mathrm{ppm}$ that corresponds to the PF6- counteranion, which is observed in all the subsequent cationic complexes derived from 3 .

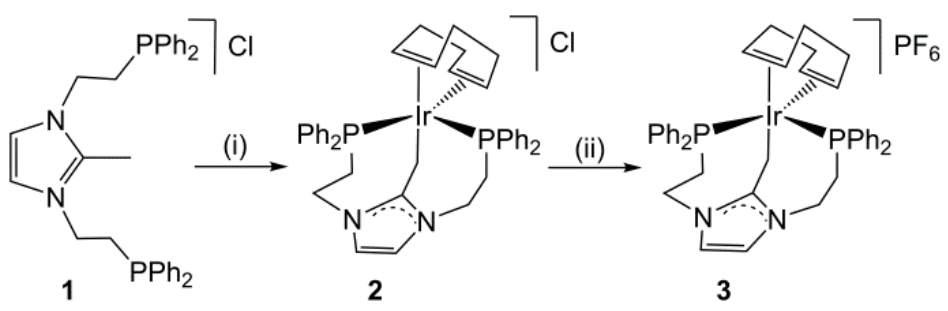

Scheme 2 Preparation of complexes 3 and 4: i) KtBuO, $[\operatorname{Ir}(\mu-\mathrm{Cl})(\operatorname{cod})] 2,25{ }^{\circ} \mathrm{C}$; ii) AgPF6 in $\mathrm{CD} 2 \mathrm{Cl} 2$.

Complex 3 was isolated by slow diffusion of pentane into a saturated dichloromethane solution. Its global connectivity pattern was confirmed by single crystal X-ray diffraction. $¥$ The 
iridium centre adopts a trigonal bipyramidal geometry (Fig. 1, left), in which a slight elongation

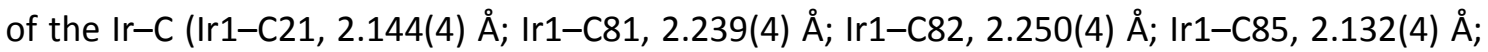

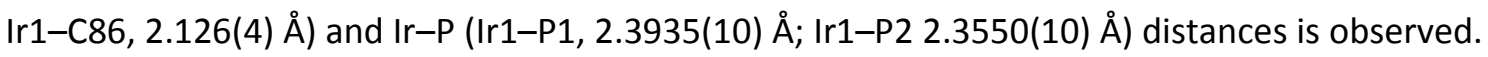
Pseudo-facial positioning of the PCP ligand 1 allows for internal P1-Ir1-P2 and Ir1-C21-C2 angles of $106.44(3)^{\circ}$ and $116.6(2)^{\circ}$, respectively. The C2-C21 distance is of $1.442(5) \AA$. Noteworthy, the carbon atoms of the $\mathrm{C}=\mathrm{C}$ bond trans to the ylidic carbon display longer $\mathrm{I}-\mathrm{C}$ bonds than those in cis position, probably due to the high trans influence expected for the NHO ligand.
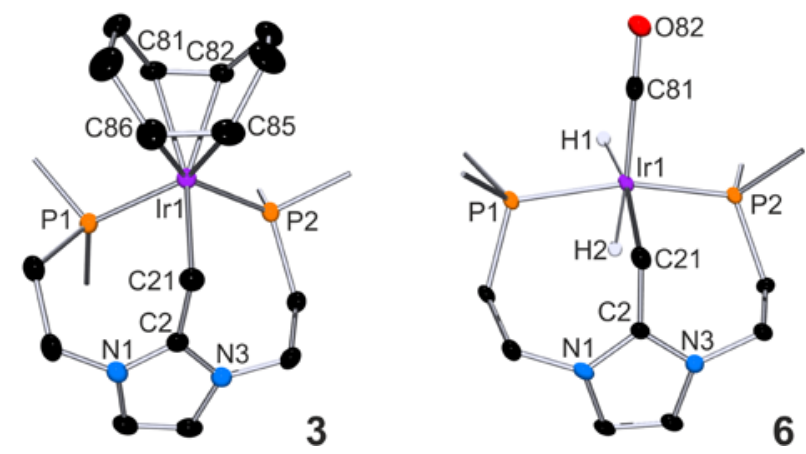

Fig. 1 View of complexes 3 and 6. The phenyl rings and PF6- counterions were omitted for clarity.

The reaction of 3 with carbon monoxide affords biscarbonyl complex [Ir(PCP)(CO)2]PF6 (4) with concomitant release of the cod ligand. 4 is stable under a carbon monoxide atmosphere, but quickly loses one of the carbonyl ligands when placed under vacuum or argon to give the $16 \mathrm{e}-$ complex 5 . The unstable nature of the biscarbonyl complex has precluded its isolation; however, it has been characterized by FT-IR and NMR spectroscopy. The IR spectrum shows two bands at 1968 (vs) and 1924 (vas) cm-1 that confirm the presence of two CO ligands. The 31P NMR spectra of 4 at $298 \mathrm{~K}$ show a sharp singlet at $\delta-9.0 \mathrm{ppm}$, which represents a significant downfield shift compared to 3 . Noteworthy, when the temperature is lowered to $188 \mathrm{~K}$ no broadening of the peak is observed. This suggests that the conformational energy barrier has a steric origin, most likely due to interactions between the phosphanes and the cod ligand. On the other hand, complex $[\operatorname{Ir}(\mathrm{PCP})(\mathrm{CO})] \mathrm{PF} 6(5)$ can be isolated and characterized, yet the very reactive nature of the complex has prevented the elucidation of its structure by X-ray crystallography. DFT optimisation predicts a square-planar geometry with the carbonyl ligand trans to the NHO (for DFT optimization see Supporting Information). In contrast with complexes $2-4$, in 5 the $\mathrm{CH} 2 \mathrm{Ir}$ resonance does not overlap with other signals in the $1 \mathrm{H}$ NMR spectra, which reveals a triplet at $\delta 2.32 \mathrm{ppm}$ due to the coupling with the two phosphanes coordinated to the Ir centre (3JP-H = $11 \mathrm{~Hz})$. This was further confirmed by the $1 \mathrm{H}\{31 \mathrm{P}\}$ NMR spectra, where this peak appears as a singlet. The two phosphorus atoms of the PCP-ligand give rise to a sharp singlet at $\delta 8.3 \mathrm{ppm}$ in the 31P NMR spectra even at low temperatures, similarly to 4 . The $13 C$ NMR and IR spectra confirm the presence of only one carbonyl ligand (凹O $181.8 \mathrm{ppm}$ and $v$ CO $1978 \mathrm{~cm}-1$ ).

When the $\mathrm{CO}$ atmosphere is displaced by a flow of $\mathrm{H} 2$ and left at room temperature for $3 \mathrm{~h}$, the bis-hydrido complex $[\operatorname{Ir}(\mathrm{PCP})(\mathrm{CO})(\mathrm{H}) 2] \mathrm{PF} 6(6)$ is formed. Complex 6 shows two triplets in $1 \mathrm{H} N M R$ at $\delta-11.03(\mathrm{JH}-\mathrm{P}=23 \mathrm{~Hz})$ and $-13.91 \mathrm{ppm}(\mathrm{JH}-\mathrm{P}=14 \mathrm{~Hz})$, which integrate one proton 
each. The two protons of the ylidic methylene group appear as an apparent doublet of triplets at $\delta 2.72 \mathrm{ppm}$ due to the coupling with the two different hydrides and the two phosphanes, which is in agreement with the $1 \mathrm{H}-1 \mathrm{H}-$ COSY NMR data. The IR spectrum proves that only one $\mathrm{CO}$ ligand remains coordinated to the iridium centre $(v C O=2066 \mathrm{~cm}-1)$. The 31P NMR spectra show a singlet and a septuplet $(1 \mathrm{JP}-\mathrm{F}=712 \mathrm{~Hz})$ at $\delta-18.0$ and $-144.3 \mathrm{ppm}$ that correspond to the PCP-ligand and the PF6- counteranion, respectively (Scheme 3 ).

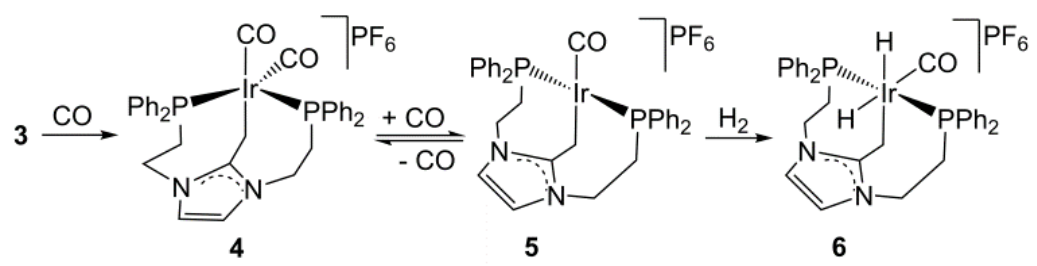

Scheme 3 Preparation of dihydride complex 6.

Crystals of 6 suitable for X-Ray diffraction where obtained by slow diffusion of pentane into a saturated dichloromethane solution. The molecular structure of cation 6 (Fig. 1, right) shows an octahedral geometry of the iridium centre, in which the PCP ligand embraces three

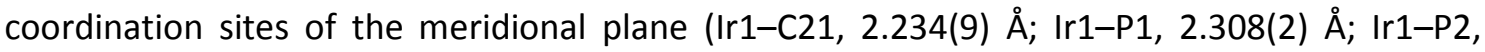
2.307(2) $\AA$ ). Additional available coordination sites are occupied by two hydride ligands (Ir1$\mathrm{H} 1,1.70(10) \AA$; Ir1-H2 1.54(9) $\AA$ ) and a CO group (Ir1-C81, 1.921(10) $\AA$ ). Interestingly, mutual trans effect of $\mathrm{H} 1$ and $\mathrm{C} 21$ atoms results in an increase of the bonding distances (Ir1-C21, 2.234(9) Å; Ir1-H1, 1.70(10) Å).

When 3 is transformed into 6 , the oxidation state of the iridium centre changes from I to III, and the geometry of the complex from trigonal bipyramidal to octahedral. Remarkably, this structural change is accompanied by an adjustment of the coordination mode of the PCP ligand from pseudo-facial in 3 to meridional in 6 . If compared to 3, intramolecular P1-Ir1-P2 $\left(162.44(8)^{\circ}\right)$ and Ir1-C21-C2 $\left(103.9(6)^{\circ}\right)$ angles show remarkable variations due to the different coordination geometry, whereas the C2-C21 distance (1.445(12) $\AA$ ) remains unaltered.

The adaptability of the ligand to different coordination geometries can be attributed to the flexible wingtip groups and the dual donor nature (ylide-olefin) of the ligand core (NHO), which can situate anywhere between the two extremes defined by the resonance forms depicted in Scheme 1. This effect has been described in the literature as a "slippage" of the metal centre along the $\square$ ond of the olefin, which has been postulated as a prerequisite for the attack of a nucleophile over a coordinated olefin. $[5,10]$ Evidences of this intermediate situation for NHO's have never been reported, in fact, to our best knowledge, this is the first example where the same olefin adopts different slippage degrees.

Theoretical calculations at the DFT level have been carried out for the investigation of the bonding in complexes 3 and 6 . Analysis of the frontier molecular orbitals of a model NHO ligand shows that the HOMO orbital predominantly corresponds to a lone pair at the $\mathrm{p}$ atomic orbital of the terminal $\mathrm{C}$ atom, while the HOMO-1 orbital represents, mainly, the $\mathrm{ClPr}-\mathrm{CH} 2 \mathrm{pi}$ double bond (Figure 2). According to this MO diagram, the NHO molecule presents two possible coordination modes to an empty d-type atomic orbital of the metal: (i) through the electron pair of the terminal carbon $\mathrm{p}$ orbital or (ii) through the $\mathrm{p} \mathrm{CIPr}-\mathrm{CH} 2$ double bond, 
reflecting the resonance structures proposed in Scheme 1. Calculation of the Wiberg bond index (WBI) for the $\mathrm{CIPr}-\mathrm{CH} 2$ bond in the free ligand gives a value of 1.52, indicating a bond order value intermediate between single and double bond. Therefore, the resonance structure I has a similar weight to structures II and III.

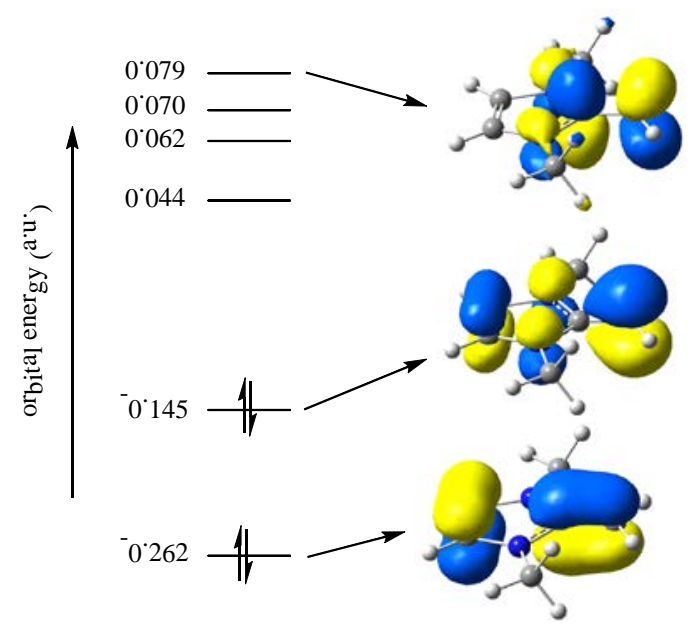

Fig. 2 Molecular orbital diagram of NHO model molecule (isocontour values of 0.05 ).

Inspection of the molecular orbitals of complexes 3 and 6 suggest that the interaction between the metal and the $\mathrm{CIPr}-\mathrm{CH} 2$ moiety takes place by donation of the lone pair at the terminal $\mathrm{C}$ into a d-type orbital of the metal (see molecular orbitals at the $\mathrm{SI}$ ). WBI of the $\mathrm{CIPr}-\mathrm{CH} 2$ bond decreases to 1.14 for complex 3 , indicating that the double bond character of the $\mathrm{CIPr}-\mathrm{CH} 2$ bond is significantly reduced upon coordination to the metal. Consequently, the NHO ligand in complex 3 can be better represented by resonance structures II and III. Remarkably, complex 6 presents a WBI for the $\mathrm{CIPr}-\mathrm{CH} 2$ bond of 1.22 , which indicates a higher degree of double bond character for the $\mathrm{CIPr}-\mathrm{CH} 2$ bond compared to that calculated for complex 3.

The theoretical study shows that the NHO molecule can donate electron density to the metal through two different mechanisms, i.e., donation by the $\mathrm{p}$ lone pair at the terminal $\mathrm{C}$ atom (HOMO) or by the pi $\mathrm{CIPr}-\mathrm{CH} 2$ double bond. Although for complexes 3 and 6 the predominant mechanism is the former, the different $\mathrm{ClPr}-\mathrm{CH} 2$ bond order values calculated for both complexes indicate the existence of intermediate situations, which illustrates the adaptability of the NHO ligand to diverse coordination environments.

In summary, we have prepared the first PCP-ligand based on an N-heterocyclic olefin. This ligand can adopt facial or meridional coordination modes thanks to the flexibility of the wingtip groups and the NHO scaffold. The latter is able to undergo subtle changes in its donor nature (ylide-olefin) in order to accommodate to the geometry of the complex. In fact, we have observed unprecedented experimental evidences of olefin "slippage" that are supported by DFT calculations.

\section{Acknowledgements}

This work was supported by the Spanish Ministry of Economy and Competitiveness (MINECO/FEDER) (CONSOLIDER INGENIO CSD2009-0050, CTQ2011-27593 and CTQ2012-35665 projects) and the DGA/FSE-E07. The support from KFUPM-University of Zaragoza research 
agreement and the Centre of Research Excellence in Petroleum Refining \& KFUPM is gratefully acknowledged. V. P. thankfully acknowledges the resources from the supercomputer "Memento", technical expertise and assistance provided by BIFI-ZCAM (Universidad de Zaragoza).

Notes and references

‡Crystal data for 1: [C64H68Cl2N4OP4], monoclinic, P21/c, a = 6.5150(5) $\AA, b=27.407(2) \AA, c=$ 16.8094(14) $\AA, \beta=97.149(2) \circ, Z=2, M r=1104.00, V=2978.1(4) \AA 33$, Dcalcd $=1.231 \mathrm{~g} \mathrm{~cm}-3$, $\lambda($ Mo K $\alpha)=0.71073 \AA, T=298 \mathrm{~K}, \mu=0.261 \mathrm{~mm}-1,40896$ reflections collected, 7372 unique (Rint $=0.0466), 4665$ observed, R1(Fo) $=0.0543[\mathrm{I}>2 \sigma(\mathrm{I})], \mathrm{wR} 2$ (Fo2) $=0.1679$ (all data), GOF = 1.002. CCDC 1402756.

Crystal data for 3: [C41H46Cl2F6IrN2P3], monoclinic, P21/c, a = 17.973(2) $\AA$, $b=11.5843(14) \AA$, $c=19.988(2) \AA ̊ \Omega, \beta=99.642(2) \stackrel{\circ}{\circ}, Z=4, M r=1036.81, V=4102.8(9) \AA ̊ 3$, Dcalcd $=1.679 \mathrm{~g} \mathrm{~cm}-3$, $\lambda($ Mo K $\alpha)=0.71073 \AA$, $T=296 \mathrm{~K}, \mu=3.562 \mathrm{~mm}-1,47105$ reflections collected, 9765 unique (Rint $=0.0890), 6799$ observed, R1(Fo) $=0.0317[\mathrm{I}>2 \sigma(\mathrm{I})], \mathrm{wR} 2$ (Fo2) $=0.0732$ (all data), GOF = 0.933. CCDC 1402757.

Crystal data for 6: [C36H40CI6F6IrN2OP3], monoclinic, P21/c, $a=11.5979(6) \AA, b=18.5435(10)$ $\AA$, $c=20.1876(11) \AA \AA$, $\beta=104.0000(10)$ o $, Z=4, M r=1128.51, V=4212.7(4) \AA ̊ 3$, Dcalcd $=1.779 \mathrm{~g}$ $\mathrm{cm}-3, \lambda(\mathrm{Mo} \mathrm{K} \alpha)=0.71073 \AA, \mathrm{T}=100 \mathrm{~K}, \mu=3.724 \mathrm{~mm}-1,50129$ reflections collected, 10123 unique (Rint $=0.0822$ ), 6985 observed, $R 1(F o)=0.0653[I>2 \sigma(I)]$, wR2 (Fo2) $=0.1575$ (all data), GOF = 1.057. CCDC 1402758 .

1 a) S. Sole, H. Gornitzka, W. Schoeller, D. Bourissou and G. Bertrand, Science, 2001, 292, 1901; b) V. Lavallo, J. Mafhouz, Y. Canac, B. Donnadieu, W. Schoeller and G. Bertrand, J. Am. Chem. Soc., 2004, 126, 8670; c) V. Lavallo, Y. Canac, B. Donnadieu, W. Schoeller and G. Bertrand, Science, 2006, 312, 722; d) V. Lavallo, Y. Ishida, B. Donnadieu and G. Bertrand, Angew. Chem., Int. Ed., 2006, 45, 6652; e) O. Schuster, L. Yang and H. G. Raubenheimer, M. Albrecht, Chem. Rev., 2009, 109, 3445.

2 a) J. Huang, H. Z. Schanz, E. D. Stevens and S. P. Nolan, Organometallics, 1999, 18, 5375; b) S. P. Nolan N-Heterocyclic Carbenes in Synthesis, Wiley-VCH, Weinheim, 2006; c) C. J. O'Brien, E. A. B. Kantchev, C. Valente, N. Hadei, G. A. Chass, A. Lough, A. C. Hopkinson and M. G. Organ, Chem. Eur. J., 2006, 12, 4743; d) F. E. Hahn, M. C. Jahnke, Angew. Chem. Int. Ed., 2008, 47, 3122; e) M. L. Clarke J. J. R. Frew in Organometallic Chemistry, ed. I. J S Fairlamb and J. M Lynam, RSC Publishing, London, 2009, vol. 35, pp. 19-46; f) L. A. Adrio and K. Kuok (Mimi) Hii in Organometallic Chemistry, ed. I. J S Fairlamb and J. M Lynam, RSC Publishing, London, 2009, vol. 35, pp. 62-92.

3 a) J. A. Osborn, F. H. Jardine, J. F. Young and G. Wilkinson, J. Chem. Soc. A, 1966, 1711; b) K. R. Jain, W. A. Herrmann and F. E. Kühn, Curr. Org. Chem., 2008, 12, 1468; c) M. Albrecht, Chem. Rev., 2010, 110, 576.

4 a) C. Johnson, R. Eisenberg, J. Am. Chem. Soc., 1985, 107, 3148; b) N. Kuhn, H. Bohnen, J. Kreutzberg, D. Bläser and R. Boese, J. Chem. Soc., Chem. Commun., 1993, 1136; c) N. Kuhn, H. Bohnen, D. Bläser and R. Boese, Chem. Ber., 1994, 127, 1405; d) A. Dumarth, X. F. Wu, H. 
Neumann, A. Spannenberg, R. Jackstell and M. Beller, Angew. Chem., Int. Ed., 2010, 49, 8988; e) S. M. I. Al-Rafia, A. C. Malcolm, S. K. Liew, M. J. Ferguson and R. McDonald, E. Rivard, Chem. Commun., 2011, 47, 6987; f) Y.-B. Wang, Y.-M. Wang, W.-Z. Zhang and X.-B. Lu, J. Am. Chem. Soc., 2013, 135, 11996.

5 A. Fürstner, M. Alcarazo, R. Goddard and C. W. Lehmann, Angew. Chem. Int. Ed., 2008, $47,3210$.

6 a) M. Albrecht and G. van Koten, Angew. Chem. Int. Ed., 2001, 40, 3750; b) M. E. van der Boom and D. Milstein, Chem. Rev., 2003, 103, 1759; c) D. Morales-Morales, Rev. Soc. Quím. Méx., 2004, 48, 338; d) H. Nishiyama, Chem. Soc. Rev., 2007, 36, 1133; e) M. Albrecht and D. Morales-Morales in Iridium Complexes in Organic Synthesis, eds. L. A. Oro and C. Claver, Wiley-VCH, Weinheim, 2009, pp. 299-321; f) J. Choi, A. H. Roy MacArthur, M. Brookhart and A. S. Goldman, Chem. Rev., 2011, 111, 1761; g) N. Selander and K. J. Szabó, Chem. Rev., 2011, 111, 2048; h) M. Albrecht and M. M. Lindner, Dalton Trans., 2011, 40, 8733; i) C. Gunanathan and D. Milstein, Chem. Rev., 2014, 114, 12024; j) M. E. O'Reilly and Ad. S. Veige, Chem. Soc. Rev., 2014, 43, 6325.

7 a) C. M. Jensen, M. W. Haenel, Chem. Commun., 1999, 2443; b) S. Oevers, K. Angermund, W. C. Kaska, H.-J. Fan and M. B. Hall, Angew. Chem. Int. Ed., 2001, 40, 3596.

8 P. Dani, T. Karlen, R. A. Gossage, S. Gladiali and G. van Koten, Angew. Chem., 2000, 112, 759; Angew. Chem. Int. Ed., 2000, 39, 743.

9 S. A. Kuklin, A. M. Sheloumov, F. M. Dolgushin, M. G. Ezernitskaya, A. S. Peregudov, P. V Petrovskii and A. A. Koridze, Organometallics, 2006, 25, 5466.

10 a) O. Eisenstein and R. Hoffmann, J. Am. Chem. Soc., 1981, 103, 4308; b) T. C. T. Chang, B. M. Foxman, M. Rosenblum and C. Stockman, J. Am. Chem. Soc., 1981, 103, 7361. 